\title{
Removal Efficiency of Treat Biogas Slurry Using Ecological Filter-Artificial Wetland Combined System under Different Hydraulic Loading
}

\author{
Renfeng TU \\ School of Resources and Environment \\ Anhui Agricultural University \\ Hefei, 230036, China \\ 113203255@qq.com \\ Jian-bo FAN \\ Institute of Soil Science \\ Chinese Academy of Science \\ Nanjing 210008, China \\ 86703645@qq.com \\ Lu HAN \\ School of Resources and Environment \\ Anhui Agricultural University \\ Hefei, 230036, China \\ 627955112@qq.com
}

\author{
Lang LANG \\ School of Resources and Environment \\ Anhui Agricultural University \\ Hefei, 230036, China \\ 1229923024@qq.com
}

\section{Jiang ZHU*}

School of Resources and Environment

Anhui Agricultural University

Hefei, 230036, China

863259529@qq.com

\begin{abstract}
The treatment effect of biogas slurry using ecological filters and the artificial wetland combination stabilization pond system under different hydraulic loading were researched. The analysis was carried out on the hydraulic load effect on the performance of the combined system, and the contribution rate of each process structure. Results showed that the combined system's load resistant capability is strong enough to provide good treatment effect, stable water and the removal efficiency with the increase of hydraulic load. Optimal removal effect under low hydraulic load was gained. Negative correlation existed between treatment effect of the artificial wetland and hydraulic load. Ecological filter on COD removal effect is better but the nitrogen and phosphorus removal efficiency of pollutants of artificial wetland is better than that
\end{abstract}

of the ecological filter.

Keywords-hydraulic loading; ecological filter-artificial wetland; removal efficiency

\section{INTRODUCTION}

In recent years, with the rapid development of the livestock, and in order to address aquaculture waste water pollution problems caused by intensive and vigorously develop the biogas project construction, biogas projects have achieved significant results [1]. However methane produces a lot of waste in the course of the project, especially biogas, which contains large amounts of pollutants, and has the characteristics of high concentration, carbon-nitrogen ratio [2,3] direct discharge of polluted the 
environment and field use and lack of fertilizer, covers an area of large, high transport costs [4]. At present, there are many large-scale farms waste liquid processing, mainly mode of aerobic treatment and natural treatment modes. Because of its high energy consumption Aerobic treatment technology covering a wide area of the shortcomings could not be promoted anaerobic treatment of relatively poor results. Natural treatment is by using ecological filters, oxidation ponds, constructed wetlands and other natural unit to handle the liquid. The pattern applies to far away from the city, broad land of farms. Eco-filter with easy management and low investment and low energy consumption are widely promoted. Eco-filter system has low concentration of liquid handling. With the effect of constructed wetland for their treatment, subsequent management is simple and has been developing rapidly. Farms are generally located in rural areas, and using artificial wetland for treatment of biogas is not only good results can be achieved, and for farms with good green environment, achieve the purpose of beautifying the environment [5]. Applying these techniques deal with liquid, and usually under certain conditions in order to achieve good results, it is difficult to maintain long-term and stable operation of the system, such as lower hydraulic capacity and longer hydraulic residence time, which requires more land. Thus, to produce a biogas process technology suitable for rural farms is of great significance. This study examines the combination of a new technology for biogas processing power, the technology in eco-filter system for the core, and with surface flow constructed wetland treatment system for subsequent processing. It Studies on combined process under different hydraulic loading effect of pollutants, further in-depth study of various units at comparison of treatment effect of pollutants, so as to provide reference for promotion process.
TABLE I. TEST RUNNING PROGRAMME

\begin{tabular}{ccc}
\hline Program & Operation times & $\begin{array}{c}\text { Hydraulic loading } \\
\left(\mathrm{m}^{3} / \mathrm{m}^{2} \cdot \mathrm{d}\right)\end{array}$ \\
\hline process1 & 7 days & 0.12 \\
process2 & 7 days & 0.18 \\
process3 & 7 days & 0.25 \\
process4 & 7 days & 0.3 \\
\hline
\end{tabular}

\section{EXPERIMENTAL APPARATUS AND METHOD}

The trial site was located in Luwang Village, Pingding Township, Yujiang County, Jiangxi Province. The biogas slurry was from the nearby farms. Firstly, the biogas slurry is pumped into the ecological filter tank through the submerged pump installed in the waste liquid pool. The biogas slurry is filtered through the primary filter. The secondary filter and the tertiary filter after the biogas filtrate enter into the surface flow constructed wetland with depth treatment. The workflow is shown in Figure I. Ecological filter for the reinforced concrete system covers an area of $12 \mathrm{~m}^{2}$, the effective volume of $9 \mathrm{~m}^{2}$. Inside the filter is divided into three consistent size, each with a diameter of $7 \mathrm{~cm}$ between the PVC pipe connected to the upper part of the biogas slurry into the first filter, and then the filtrate from the bottom up into the next level. Three-stage filter tank has different fillers. The first level of filling material for the $5 \sim 10 \mathrm{~mm}$ gravel. The second filter is two layers. The bottom of the 20 30mm pebble as a supporting layer covered with $2 \sim 4 \mathrm{~mm}$ gravel; Third pole media is divided into three layers, that is, on the basis of the second filter with sand. The wetland is a three-level surface flow wetland, and each level is connected with a drainage channel. The wetland has a variety of aquatic crops such as barracuda, calamus, Canna indica, re-flower and so on. 


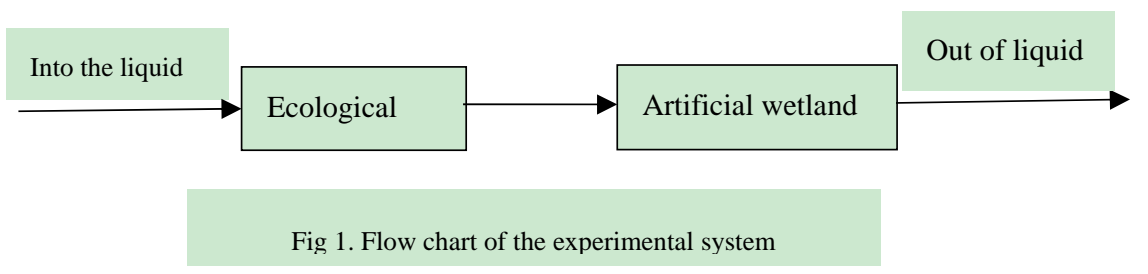

In this test, the hydraulic loading of the combined process is adjusted by adjusting the feed rate. The hydraulic loading and test arrangement of the combined process are shown in Table I. Throughout the test run, the process using intermittent water, 8:00 every morning into the liquid, stop at four o'clock every day into the liquid $6 \mathrm{~h}$ (ie, the wet to dry ratio of 2:1) test sequence from low load to high load operation.

Water sampling frequency of $1 / 2$ days, sampling time at four in the afternoon, the sampling container for the $500 \mathrm{ml}$ polyethylene bottle. Water monitoring indicators are COD, $\mathrm{TN}, \mathrm{NH}_{4}^{+}-\mathrm{N}$, TP. Water quality monitoring indicators and methods in Table II, the specific method of measurement see "water and wastewater monitoring and analysis methods [6].

TABLE II INDEX AND METHOD OF WATER SAMPLE MONITORING

\begin{tabular}{cc}
\hline $\begin{array}{c}\text { Monitoring } \\
\text { indicators }\end{array}$ & Measurement methods \\
\hline PH & Glass electrode method \\
COD & Potassium dichromate method \\
TN & Potassium persulfate oxidation spectrophotometric \\
$\mathrm{NH}_{4}{ }^{+}-\mathrm{N}$ & Nessler's reagent photometric method \\
$\mathrm{TP}$ & Ammonium molybdate spectrophotometric method \\
\hline
\end{tabular}

\section{RESULTS AND ANALYSIS}

\section{A. Combined Process of Treatment Effect}

1) The effect of different hydraulic loading on COD removal

The removal of COD was mainly through the adsorption of plant root and substrate surface biofilm, and then was degraded by microorganism ${ }^{[7]}$. After the stable combination process , the COD removal effect is shown in Table III. It can be seen from the table and the lowest concentration of influent COD in the combined system is $100.37 \mathrm{mg} / \mathrm{L}$;

the highest is $109.76 \mathrm{mg} / \mathrm{L}$, the average concentration is $105.67 \mathrm{mg} / \mathrm{L}$; and the concentration of COD in effluent is fluctuant; the lowest is $20.86 \mathrm{mg} / \mathrm{L}$; the highest was 64.81 $\mathrm{mg} / \mathrm{L}$; the average effluent concentration was $42.04 \mathrm{mg} / \mathrm{L}$. The effluent quality reaches Grade B standard.

TABLE III THE REMOVALE EFFICIENCY UNDER DIFFERENT HYDRAULIC LOADING OF COD

\begin{tabular}{cccc}
\hline \multirow{2}{*}{$\begin{array}{c}\text { Hydraulic } \\
\text { loading }\end{array}$} & \multicolumn{3}{c}{ Concentration of COD $\left(\mathrm{O}^{2}, \mathrm{mg} / \mathrm{L}\right)$} \\
\cline { 2 - 4 }$\left(\mathrm{m}^{3} / \mathrm{m}^{2} \cdot \mathrm{d}\right)$ & Into the & Filter out the & Wetlands out of \\
& liquid & liquid & liquid \\
\hline 0.12 & 109.76 & 56.64 & 20.86 \\
0.18 & 109.76 & 53.54 & 31.54 \\
0.25 & 102.79 & 66.28 & 50.95 \\
0.3 & 100.37 & 72.37 & 64.81 \\
\hline
\end{tabular}

\section{2) Different hydraulic load and $T N$ removal effect}

The nitrogen content in the biogas slurry is an important factor causing the eutrophication of the water body, and its removal is mainly nitrification and denitrification, plant absorption and ammonia volatilization and other means. The lower anaerobic space of bio-filter is favorable for the denitrification, and the oxygen supply in the plant roots in the constructed wetland produces aerobic space, which is favorable to the nitrification reaction ${ }^{[9]}$.

The experimental results showed that the influent concentration of $\mathrm{TN}$ was $94.46 \sim 106.55 \mathrm{mg} / \mathrm{L}$, and the average concentration was $101.96 \mathrm{mg} / \mathrm{L}$; the TN concentration of effluent was $32.56 \mathrm{mg} / \mathrm{L}$, and the mean value was $27.76 \mathrm{mg} / \mathrm{L}$. The effluent quality meets the requirements of the $\mathrm{TN}$ standard for the pollutant discharge standard of urban sewage treatment plant (GBl8918-2002). 
The results show that the combined process has good removal effect under different hydraulic loading.

TABLE IV THE REMOVALE EFFICIENCY UNDER DIFFERENT HYDRAULIC LOADING OF TN

\begin{tabular}{cccc}
\hline \multirow{2}{*}{$\begin{array}{c}\text { Hydraulic } \\
\text { loading }\end{array}$} & \multicolumn{3}{c}{ Concentration of $\mathrm{TN}(\mathrm{mg} / \mathrm{L})$} \\
\cline { 2 - 4 }$\left(\mathrm{m}^{3} / \mathrm{m}^{2} \cdot \mathrm{d}\right)$ & $\begin{array}{r}\text { Into the } \\
\text { liquid }\end{array}$ & $\begin{array}{c}\text { Filter out the } \\
\text { liquid }\end{array}$ & $\begin{array}{c}\text { Wetlands out of } \\
\text { liquid }\end{array}$ \\
\hline 0.12 & 106.55 & 98.6 & 24.72 \\
0.18 & 101.85 & 92.9 & 24.12 \\
0.25 & 94.46 & 85.55 & 32.56 \\
0.3 & 105 & 96.08 & 29.64 \\
\hline
\end{tabular}

3) Different hydraulic loading and $N H 4+-N$ removal effect

TABLE V THE REMOVALE EFFICIENCY UNDER DIFFERENT HYDRAULIC LOADING OF $\mathrm{NH}_{4}{ }^{+}-\mathrm{N}$

\begin{tabular}{cccc}
\hline \multirow{2}{*}{$\begin{array}{c}\text { Hydraulic } \\
\text { loading }\end{array}$} & \multicolumn{3}{c}{ Concentration of $\mathrm{NH}_{4}{ }^{+}-\mathrm{N}(\mathrm{mg} / \mathrm{L})$} \\
\cline { 2 - 4 }$\left(\mathrm{m}^{3} / \mathrm{m}^{2} \cdot \mathrm{d}\right)$ & $\begin{array}{c}\text { Into the } \\
\text { liquid }\end{array}$ & $\begin{array}{c}\text { Filter out the } \\
\text { liquid }\end{array}$ & $\begin{array}{c}\text { Wetlands out of } \\
\text { liquid }\end{array}$ \\
\hline 0.12 & 27.45 & 24.2 & 5.95 \\
0.18 & 29.72 & 23.2 & 8.06 \\
0.25 & 16.95 & 13.81 & 6.19 \\
0.3 & 30.72 & 27.42 & 12.49 \\
\hline
\end{tabular}

The results showed that the concentration of $\mathrm{NH}_{4}{ }^{+}-\mathrm{N}$ in influent was between $16.95 \sim 30.72 \mathrm{mg} / \mathrm{L}$. The average value was $26.21 \mathrm{mg} / \mathrm{L}$. The concentration of $\mathrm{NH}_{4}{ }^{+}-\mathrm{N}$ in effluent was between $5.95 \sim 12.49 \mathrm{mg} / \mathrm{L}$ and the average value was $8.17 \mathrm{mg} / \mathrm{L}$ and the average removal rate of $68 \%$. The effluent quality meets the requirement of $\mathrm{NH}_{4}{ }^{+}-\mathrm{N}$ in the standard of Class B of GB1889-2002, which can meet Grade A standard at low load. Indicating that the combined process has good removal effect on NH4+-N under different hydraulic loading.

\section{4) Different hydraulic load and TPremoval effect}

Phosphorus removal is mainly matrix adsorption, plant self-assimilation, root interception, chemical precipitation, etc. [10-11]. The hydraulic loading increases and the flow retention time is short, leading to a decrease in the settling performance of phosphorus [12]. As shown in Table VI, the concentration of total phosphorus in effluent was between 17.70 and $30.94 \mathrm{mg} / \mathrm{L}$, the average concentration was $23.95 \mathrm{mg} / \mathrm{L}$, and the total phosphorus concentration in effluent was $5.42-14.12 \mathrm{mg} / \mathrm{L}$ range to reach the "urban sewage treatment plant pollutant discharge standards" (GBl8918-2002) three standard. The average removal rate of total phosphorus can reach $61 \%$.

TABLE VI THE REMOVALE EFFICIENCY UNDER DIFFERENT HYDRAULIC LOADING OF TP

\begin{tabular}{cccc}
\hline Hydraulic & \multicolumn{3}{c}{ Concentration of TP $(\mathrm{mg} / \mathrm{L})$} \\
loading & \multicolumn{3}{c}{} \\
\cline { 2 - 4 }$\left(\mathrm{m}^{3} / \mathrm{m}^{2} \cdot \mathrm{d}\right)$ & $\begin{array}{c}\text { Into the } \\
\text { liquid }\end{array}$ & Filter out the & Wetlands out of \\
& 19.34 & 14.08 & liquid \\
\hline 0.12 & 17.7 & 14.08 & 5.42 \\
0.18 & 27.83 & 24.65 & 6.36 \\
0.25 & 30.94 & 27.73 & 12.88 \\
0.3 & & & 14.12 \\
\hline
\end{tabular}

\section{B. System Unit Processing Effect}

1) Different units under the hydraulic load of the treatment effect

As shown in Fig.2-1, Fig.2-2 and Fig.2-3, the removal rates of pollutants in ecological filter and constructed wetland are all negatively correlated with hydraulic load and weakened with increasing hydraulic load. When the removal rate is high, high load is low. This is consistent with Chen Jianjun et al. [13] that the process system under different hydraulic loading is consistent with the trend of pollutant removal. The reason may be the high hydraulic load, and the biogas slurry flow through the filter is too short, so the effect of sedimentation decreased, coupled with the lack of dissolved oxygen, resulting in decreased pollutant removal rate. 


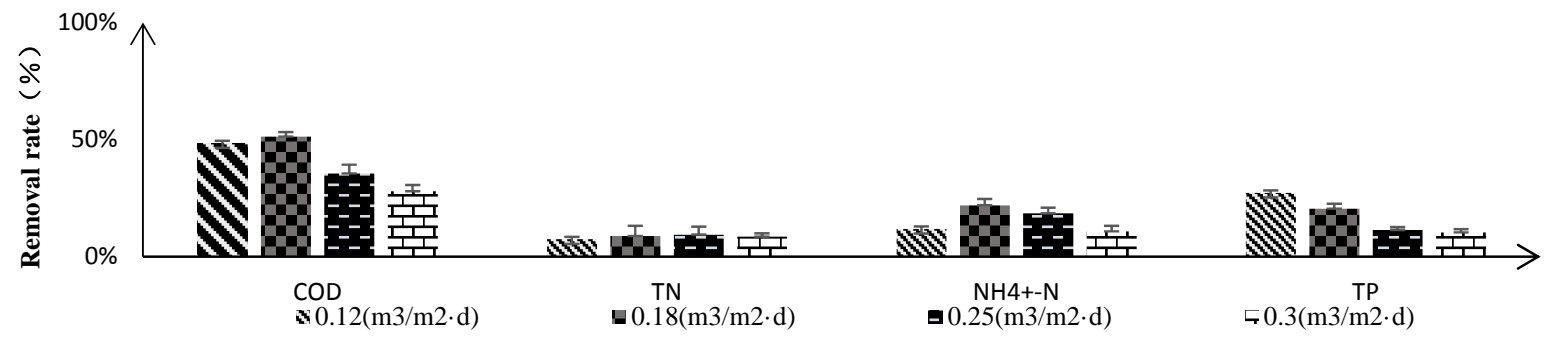

Fig 2. Removal rate of pollutants under different hydraulic load

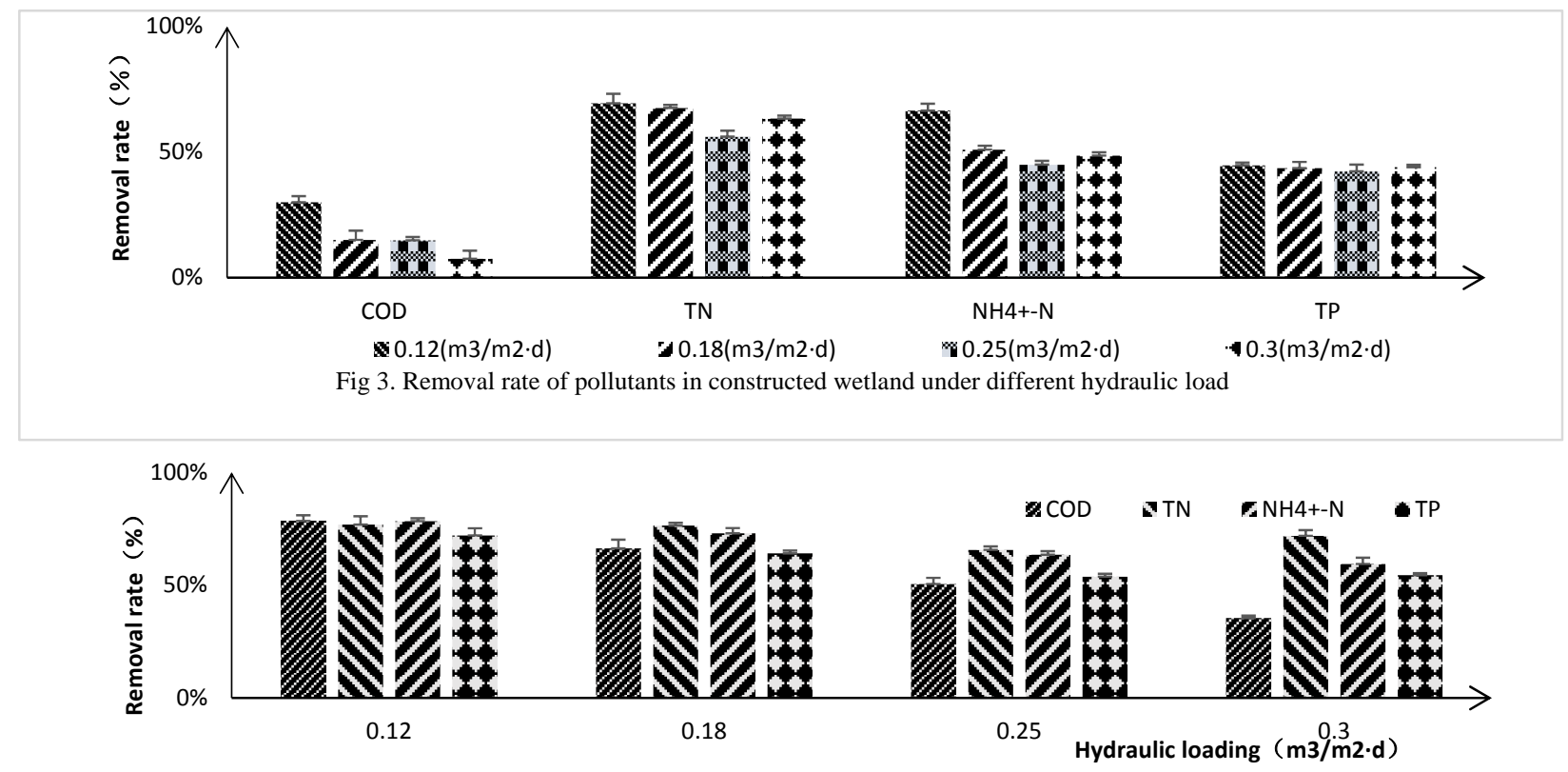

Fig 4. Removal rate of pollutants by combined process under different hydraulic load

2) the same hydraulic load unit treatment effect comparison

It can be seen from Table VII that, under different hydraulic loading, the removal efficiency of COD by ECF is better than that of constructed wetland, which shows that ECF can resist organic load effectively and can be effective under different hydraulic loads Removal. The average removal rate was $40.66 \%$ and the highest was $51.22 \%$. But for the removal of nitrogen and phosphorus pollutants, the constructed wetlands under different hydraulic loading were higher than the ecological filter, indicating that the constructed wetlands could remove nitrogen and phosphorous pollutants in depth and reach stable water. Because the substrate, microorganisms and plants in the constructed wetland are simultaneously with the biogas slurry, it can effectively degrade the pollutants. 
TABLE VII. REMOVAL RATE OF POLLUTANTS UNDER DIFFERENT HYDRAULIC LOADING UNITS (\%)

\begin{tabular}{|c|c|c|c|c|c|c|c|c|}
\hline \multirow{2}{*}{ item } & \multicolumn{2}{|c|}{$0.12 \mathrm{~m}^{3} / \mathrm{m}^{2} \cdot \mathrm{d}$} & \multicolumn{2}{|c|}{$0.18 \mathrm{~m}^{3} / \mathrm{m}^{2} \cdot \mathrm{d}$} & \multicolumn{2}{|c|}{$0.25 \mathrm{~m}^{3} / \mathrm{m}^{2} \cdot \mathrm{d}$} & \multicolumn{2}{|c|}{$0.30 \mathrm{~m}^{3} / \mathrm{m}^{2} \cdot \mathrm{d}$} \\
\hline & Filter & Wetlands & Filter & Wetlands & Filter & Wetlands & Filter & Wetlands \\
\hline COD & 48 & 30.02 & 51.22 & 15.06 & 35.52 & 14.91 & 27.9 & 7.53 \\
\hline $\mathrm{TN}$ & 7.46 & 69.34 & 8.79 & 67.53 & 9.43 & 56.1 & 8.5 & 63.28 \\
\hline $\mathrm{NH}_{4}^{+}-\mathrm{N}$ & 11.84 & 66.48 & 21.94 & 50.94 & 18.49 & 44.96 & 10.76 & 48.58 \\
\hline $\mathrm{TP}$ & 27.22 & 44.74 & 20.48 & 43.56 & 11.43 & 42.28 & 10.38 & 43.97 \\
\hline
\end{tabular}

\section{DISCUSSION}

The removal rates of $\mathrm{TN}, \mathrm{NH}_{4}{ }^{+}-\mathrm{N}$ and $\mathrm{TP}$ were significantly higher than those of the other treatments when the hydraulic loading was $0.18 \mathrm{~m}^{3} / \mathrm{m}^{2} \cdot \mathrm{d}$. The optimal removal load of COD is $0.250 .18 \mathrm{~m} 3 / \mathrm{m} 2 \cdot \mathrm{d}$. And Owen $\mathrm{TaO}^{[14]}$ combined layered biofilter and artificial wetland in the process of different hydraulic loading on the pollutant removal effect of the same trend.

In addition, the waste biogas slurry has medium concentration of organic matter and COD has a high biochemical characteristics, through the ecological filter and constructed wetland two-stage treatment, the removal efficiency reached $80 \%$. The results showed that the nitrification of microorganisms in the wetland was inhibited by the carbon source deficiency when the COD: $\mathrm{N}<10$ [15] or $\mathrm{C}: \mathrm{N}<5$ [16-17] in the biogas slurry, which affected the removal of nitrogen .

The removal of phosphorus mainly occurred in the constructed wetland, probably due to the high concentration of dissolved phosphate in the wastewater. In addition, the biofilter was mainly composed of sand, and its ability to adsorb phosphorus was relatively low [18] . At the same time, the adsorption of phosphorus on the matrix generally conforms to the Langmuir and Freunlich isotherm equation. Under the high concentration of phosphorus, the adsorption capacity is limited and the saturation is reached in a short time[19-20].Therefore, the phosphorus removal capacity limited.

\section{CONCLUSION}

The ecological filter-constructed wetland has a good effect of removing contaminants and strong ability of resisting load and It can stabilize the water in different hydraulic loads. COD and $\mathrm{NH}_{4}{ }^{+}-\mathrm{N}$ meet GB18198-2002 in the first B standard; total nitrogen and total phosphorus, respectively, can add to two and three standard.

The hydraulic load has a certain influence on the combined process. The removal rate of the combined process was negatively correlated with the hydraulic load, and the removal rate of the pollutants decreased with the increase of the hydraulic loading, and the removal efficiency was the best under low hydraulic loading.

The treatment effect of each unit in combination process is different. Under the same hydraulic load, the removal efficiency of COD was better than that of constructed wetland, and the effluent could be removed efficiently. However, the treatment effect of constructed wetland was better than that of ecological filter. Phosphorus contaminants can be deeply degraded to ensure effluent.

\section{REFERENCES}

[1] YANG Xu, LI Wenzhe, SUN Yong, WANG Xiaowei. Experimental study on purification effect of wastewater from livestock and poultry containing biogas slurry by constructed wetland system [J] .Acta Ecologica Sinica, 2012,03: 515-517.

[2] Kaparaju P, Rintala J. Effects of solid-liquid separation on recovering residual methane and nitrogen from digested dairy cow manure [J]. Bioresource Technology, 2008, 99 (1): 120-127

[3] Zhang Zhaoji, Li Yuanyuan, Chen Shaohua, et al. Simultaneous nitrogen and carbon removal from swine digester liquor by the Canon process and denitrification [J]. Bioresource Technology, 2012, 114: 84-89

[4] Sui Qianwen, Dong Hongmin, Zhu Zhiping, Guo Dongpo. Ammonia Stripping Control Parameters to Improve the Effect of Biogas Purification Treatment on Pig Farm [J] .Chinese Journal of Agricultural Engineering, 2012,11: 205-211.

[5] Hu Fengmei Ex Experimental Study on Treatment of Biogas Wastewater from Swine Farm by Constructed Wetland [D]. Chengdu University of Technology, 2012..

[6] State Environmental Protection Administration. Water and wastewater monitoring and analysis methods (fourth edition). Beijing: 
China Environmental Science Press, 2002

[7] Xie Long, Wang Dejian, Dai Yu. Studies on Organic Matter Removal Model in Horizontal Subsurface Flow Constructed Wetlands [J] .Chinese Journal of Environmental Science, 2009,05: 502-505.

[8] Lee C. G. , Fletcher T. D. , Sun Guangzhi. Nitrogen removal in constructed wetland systems. Engineering in Life Sciences, 2009, 9 (1): $11-22$

[9] TANG Hao, XUE Xue-Min, ZHOU Cui-Shi. Improvement of Surface Flow Constructed Wetland Design and Study on Wastewater Purification Effect [J] .Acta Agricolutica Sinica, 2005, S1: 125-129.

[10] Lu Shaoyong, Kim Sang-Can, Yu Gang. Removal Mechanism of Phosphorus in Constructed Wetland. Ecological environment, 2006, 15 (2): 391-396

[11] Cui Lijuan, Li Wei, Zhang Manyin, et al. Contribution of Different Wetland Plants to Nitrogen and Phosphorus Removal in Sewage. Lakes Science, 2011, 23 (2): 203-208

[12] CUI Fang. Study on influence of temperature change on purification of urban lake water by constructed wetland [J]. Water Conservancy Science and Technology, 2010,09: 982-983 + 985

[13] CHEN Jian-jun, XI Yin, LIAO Zai-yi, et al. Effects of hydraulic loading and air temperature on gray water treatment in farm households [J] .Acta Agriculturae Scientia Sinica. 2010, 20 (10): 2012-2018

[14] Ou Wentao, Li Xudong, Pang Haoran, Dai Yiqi, Qiu Jiangping. Experimental study on the treatment of rural domestic wastewater by combined layered biofilter and artificial wetland [J]., 2009,04: 28-31.
[15] Dai Yanran, Liang Wei, Wu Zhenbin. Study on Nitrogen Removal from Constructed Wetland in Low Carbon and High Nitrogen Wastewater [J] .Acta Agricolutica Sinica, 2010, S1: 305-309.

[16] ZHU Wen-Ling, ZHENG Li-Ni, CUI Li-Hua, OUYANG Ying, LUO Shi-Ming, TANG Zhong-En. Effects of Four Controllable Factors on Total Nitrogen Removal in Vertical Flow Constructed Wetlands under Different C / N Ratios [J] .Acta Agriculturae Scientia Sinica, 2010,06 : 1187-1192.

[17] Ingersoll T. Respectively. , Baker L. A. Nitratfe removal in wetland microcosms. Water Research, 1998, 32 (3): 677-684

[18] Li Xiaodong, Sun Tieheng, Li Haibo, Wang Hong. Research Progress of Phosphorus Removal in Constructed Wetlands [J] .Acta Ecologica Sinica, 2007,03: 1226-1232.

[19] Liu Bo, Chen Yucheng, Wang Liwei, He Juan, Liu Jiangguo, Liang Qinshuang. Adsorption characteristics of four kinds of constructed wetland fillers for phosphorus adsorption [J] .Techniques and Equipment for Environmental Pollution and Control, 2010,01: 44-48.

[20] Wang Zhen, Liu Chaoxiang, Dong Jian, Liu Lin, Li Pengyu, Zheng Jiayu Screening of Phosphorus Removal Filler in Constructed Wetland and Its Phosphorus Removal Ability [J] .Chinese Journal of Environmental Science, 2013,02: 227-233. 